\title{
Water resistance of thermal insulation composites with cellulose-containing filler
}

\author{
Irina Susoeva ${ }^{1 *}$, Tatiana Vakhnina $^{1}$, Andrey Titunin ${ }^{1}$, and Yuri Grunin ${ }^{2}$ \\ ${ }^{1}$ Chair Logging and Processings of Wood of Productions, Kostroma State University, 17, \\ Dzerzhinsky, Kostroma 156005, Russia \\ ${ }^{2}$ Physics department Volga State Technical University, 3, Lenin square, Yoshkar-Ola 424000, Russia
}

\begin{abstract}
One of the urgent tasks is the development of new thermal insulation materials to improve the energy efficiency of construction. In this work, new composites were obtained based on previously unused cellulose-containing waste. The theoretical and experimental substantiation of the possibility of increasing the water resistance of the heat-insulating composite has scientific significance. The features of the supramolecular structure of cellulose are analyzed. As a result of studies of the process of structure formation of a new heat-insulating material, it has been established that to ensure stable heat-insulating properties of composites from cellulose-containing waste, it is advisable to use a phenolformaldehyde binder, water glass, or alumochromophosphate. The developed composite has a swelling $2.7 \quad \ldots \quad 3$ times less, and water absorption $2.2 \ldots 2.4$ times less than mineral wool slabs. The coefficient of thermal conductivity of the new composite material, depending on the type of cellulose-containing filler, ranges from 0.076 to $0.092 \mathrm{~W} / \mathrm{m} \cdot \mathrm{K}$, which makes it possible to recommend it for use in thermal protection of buildings.
\end{abstract}

\section{Introduction}

The issues of ensuring sustainable innovative development of the construction industry, improving the energy efficiency of buildings and structures have been relevant for over 20 years. According to the Energy Strategy of Russia for the period up to 2030, the amount of unrealized energy saving potential is $40 \%$, therefore, as S. V. Fedosov and his colleagues, it is necessary to carry out the design of buildings, focused on reducing energy consumption [1]. At the same time, according to the scientists of the Moscow University of Civil Engineering, the new construction technological order should be based on the development of innovations in construction, focused on resource conservation and the use of new, previously unused resources [2]. The use of industrial waste for the production of new types of energy efficient materials solves, in fact, the problem of ensuring a stable state of the system "society - environment - construction site - ecosystem" [3].

The energy efficiency of building structures primarily depends on the building materials used, while the choice of a heat-insulating material with stable heat transfer resistance is

*Corresponding author: i.susoeva@yandex.ru 
essential. It must also ensure the stability of the operational parameters of the enclosing structure and also have a certain operational resistance, i.e. the ability to withstand operational loads for a long time, including humidity influences, without significant changes in properties [4].

In the field of creating energy-efficient building materials, numerous studies have been and are being carried out in MGSU and other specialized organizations. At the same time, most authors adhere to the concept of developing composite materials with the required parameters and properties based on interdisciplinary research and the integration of knowledge from various branches of science $[5,6]$.

The aim of the study is to develop heat-insulating cellulose-containing board materials with reduced sorption of water and moisture. To achieve the goal of the study, the question of increasing the water resistance of a new heat-insulating material was raised.

The choice of the material for the elements of the thermal insulation structure is based on regulatory requirements. According to the Russian standard 50.13330.2012, the durability of the enclosing structures should be ensured by using materials that have the necessary resistance to temperature and humidity.

During the operation of buildings, the temperature and humidity conditions and structural indicators of heat-insulating materials have a great influence on the heat-shielding properties of the enclosing structures. The thermal resistance of the building envelope depends to a large extent on the thermal conductivity of the materials. Thermal insulation materials with cellulose-containing filler are characterized by the interconnection of thermophysical properties and the macro- and supramolecular structure of the material. A change in the moisture content of wood and other materials based on vegetable fillers affects the thermophysical indicators of the constituent elements and the entire structure as a whole [7]. With an increase in moisture content, the thermal resistance of the enclosing structure decreases, and the density of the heat flux through the wall increases. This dependence is even more characteristic in the presence of embedded parts in the design [8].

Based on these patterns, the purpose of the study is to develop heat-insulating cellulosecontaining board materials with reduced sorption of water and moisture.

For cellulose-containing materials, as well as for other materials of enclosing structures, with an increase in moisture content, the thermal conductivity of the material increases almost linearly [9]. Under variable temperature and humidity effects of the environment, not only the thermal conductivity of the cellulose-containing material changes, but also its strength decreases. The decrease in the strength of heat-insulating elements under changing temperature and humidity conditions is described by polynomials of varying degrees, depending on the structure of the material [10].

The relationship between the variable temperature and humidity effects of the environment and the thermophysical parameters of cellulose-containing materials is based on the peculiarities of the supramolecular structure of cellulose. The supramolecular structure determines all the basic physical and mechanical properties of cellulose, and hence of cellulose-containing composites. Cellulose microfibril consists of monocrystalline regions with stronger hydrogen bonds and polycrystalline regions with weaker hydrogen bonds. The interlayer distances between the polycrystalline regions are about $0.4 \mathrm{~nm}$. The weakness of intermolecular hydrogen bonds between polycrystalline regions is the reason for the formation of slit-like micropores [11]. When exposed to moisture, sorbed water fills micropores, then submicropores, mesopores and voids in the structure [12], and the physical characteristics of the cellulose-containing filler material change $[13,14]$. The wedging action of a monolayer of water in the amorphous region of cellulose leads to swelling of the material $[15,16]$. 
Thus, the problem of increasing the water resistance of heat-insulating cellulosecontaining composites must be solved, taking into account the properties of fillers and matrix-binder, as well as their influence on the formation of the composite structure.

\section{Methods}

Research in the field of increasing the resistance of composite board materials for thermal insulation purposes to moisture influences was carried out in the laboratory of the Kostroma State University (KSU), Kostroma, Russia. The paper investigates the physical and thermal properties of composites of soft wood waste and irrecoverable waste of spinning flax and cotton based on a matrix of synthetic and inorganic binders. Samples of the composite were made using the technology of wet fiberboards by mixing vegetable filler with water, a binder, molding, squeezing and drying at a temperature of $100^{\circ} \mathrm{C}$. Phenol-formaldehyde binder PFB-3014 (PFB), urea-formaldehyde binder (UFB), liquid glass $\mathrm{Na}_{2} \mathrm{O}\left(\mathrm{SiO}_{2}\right) \mathrm{n}$, and alumochromophosphate $\mathrm{CrAl}_{3}\left(\mathrm{H}_{2} \mathrm{PO}_{4}\right)$ n were used as binders. The composite material was made with an average density of $275 \mathrm{~kg} / \mathrm{m}^{3}$, the consumption of the binder was $30 \%$ by weight of the filler.

The IR spectra of material samples were recorded on a NETZSCH STA 449 F3 Jupiter synchronous thermal analysis setup combined with an IR Fourier attachment.

To determine the thermophysical properties of the composites, a stationary method was used, in which a constant heat flux is formed through the sample over time. Investigations of the thermal conductivity coefficient of composite materials based on cellulosecontaining waste were carried out using the ITP-MG-4 thermal conductivity meter in accordance with the Russian standard 7076-99 "Building materials and products. Method for determining thermal conductivity and thermal resistance in a stationary thermal regime". The accuracy of determining the thermal conductivity coefficient is $\pm 0.002 \mathrm{~W} /(\mathrm{m} \cdot \mathrm{K})$.

\section{Results and Discussion}

The authors' studies have shown that the properties of composites from plant waste significantly depend on the type of filler [21]. The highest water absorption values are for wood chips and linen and cotton fiber boards. For wood waste, this is due to significant fiber damage, increased absorbency of the binder and, as a consequence, a small number of adhesive contacts between filler particles. For flax and cotton fibers, the reason is the low mobility of cellulose macromolecules with a high degree of polymerization, which makes it difficult to form hydrogen bonds during the structure formation of the composite. The presence of fatty and waxy substances on the surface of the fibers also affects the formation of chemical bonds with the thermosetting binder. Composites of other vegetable fillers have physical characteristics comparable to those of an analogue material - soft heat-insulating wood-fiber boards. Indicators of composite plates from vegetable waste are given in Tables $1,2$.

In this work, the IR spectra of cellulose-containing waste and composites based on them were obtained. Some of the IR spectra (cotton waste and cotton waste composite on liquid glass) are shown in Fig. 1, 2. The absorption bands for the obtained spectra are presented in Tables 3-7. 


\begin{tabular}{|c|c|c|c|c|}
\hline \multicolumn{6}{|c|}{ Table 1. Physical and mechanical properties and thermal conductivity of composites of plant particles } \\
and polycondensation binders *
\end{tabular}

* Above the line on phenol-formaldehyde binder, below the line on urea-formaldehyde binder

Table 2. Physical and mechanical properties and thermal conductivity coefficient of composites of plant particles and inorganic binders *

\begin{tabular}{|c|c|c|c|c|}
\hline Composite filler & $\begin{array}{l}\text { Swelling in } \\
\text { thickness, \% }\end{array}$ & $\begin{array}{c}\text { Water } \\
\text { absorption, \% } \\
\end{array}$ & $\begin{array}{l}\text { Density, } \\
\mathrm{kg} / \mathrm{m}^{3}\end{array}$ & $\begin{array}{l}\text { Thermal conductivity } \\
\text { coefficient, } \mathrm{W} /(\mathrm{m} \cdot \mathrm{K})\end{array}$ \\
\hline Waste cotton & $\frac{13.9}{13.8}$ & $\frac{155}{153}$ & $\frac{249}{251}$ & $\frac{0.089}{0.089}$ \\
\hline Flax waste & $\frac{8.1}{8.0}$ & $\frac{127}{140}$ & $\frac{259}{261}$ & $\underline{0.076}$ \\
\hline $\begin{array}{c}\text { Flax waste }+ \text { softwood } \\
\text { shavings }\end{array}$ & $\frac{11.9}{11.7}$ & $\frac{135}{131}$ & $\frac{272}{275}$ & $\frac{0.081}{0.081}$ \\
\hline $\begin{array}{c}\text { Waste cotton }+ \\
\text { softwood shavings }\end{array}$ & $\frac{18.4}{18.1}$ & $\frac{153}{150}$ & $\frac{266}{268}$ & $\frac{0.092}{0.092}$ \\
\hline
\end{tabular}

* Above the line on liquid glass, below the line on alumochromophosphate

Materials based on cotton and linen fibers have the lowest density and the lowest coefficient of thermal conductivity (of the considered compositions). The thermal conductivity coefficient for them is comparable to this parameter of mineral wool slabs. According to V. P. Yartseva water absorption of mineral wool slabs reaches $80 \ldots 300 \%$ [22]. However, from an economic point of view, it is preferable to use finely dispersed irrecoverable cellulose-containing waste for the production of thermal insulation boards. Composites from flax waste and from flax waste and softwood shavings have the best indicators. The addition of wood chips to flax waste increases thickness swelling, however for both composites the thickness swelling is $2.7 \ldots 3$ times less than that of mineral wool slabs, water absorption is $2.2 \ldots 2.4$ times less than for mineral wool boards.

The use of the cheapest and the largest-tonnage binder, urea-formaldehyde, as a matrix, does not allow obtaining a material with the necessary balance of physical and operational parameters. 
The composite based on phenol-formaldehyde binder and inorganic binders (liquid glass, alumochromophosphate) has a high stability of physical characteristics when exposed to water.

Liquid glass and alumochromophosphate make it possible to obtain composites with lower water absorption and thickness swelling than polycondensation binders. These dependences characterize the IR spectra of the filler material (Figure 1, Table 3) and composites (Figure 2, Tables 4-7). The absorption intensity in the range of $1630 \ldots 1650 \mathrm{~cm}^{-}$ 1 , characteristic of deformation vibrations of bonds in $\mathrm{H}-\mathrm{O}-\mathrm{H}$ molecules, due to the presence of bound water, in comparison with the initial spectrum of cotton waste, decreases in composites based on inorganic binders by 1.3...1.5 times. In the composite based on PFS, the absorption intensity due to bound water is comparable to the parameter for the spectrum of the filler, and in the composite based on urea-formaldehyde binder it exceeds this value. This is due to the presence of unreacted methylol groups in the cured polycondensation binders, which are capable of attaching free moisture.

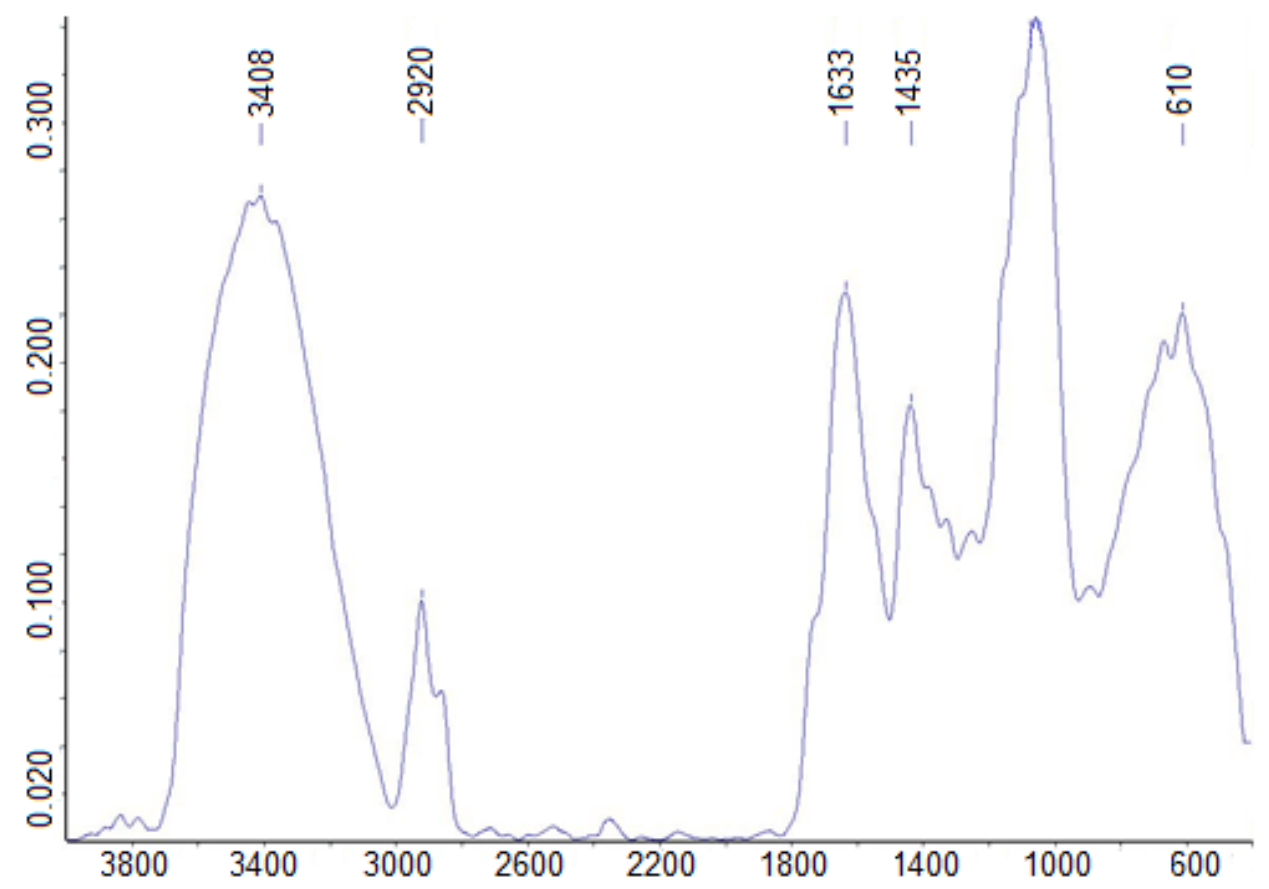

Fig. 1. IR spectrum of cotton waste.

\begin{tabular}{|c|c|c|}
\hline \multicolumn{3}{|r|}{ Table 3. Cotton waste absorption bands } \\
\hline $\begin{array}{c}\text { Band position, } \\
\mathrm{cm}^{-1}\end{array}$ & $\begin{array}{l}\text { Absorption } \\
\text { intensity, } \%\end{array}$ & Assignment of absorption bands \\
\hline 3408 & 0.27 & $\begin{array}{l}\text { Stretching vibrations of } \mathrm{OH} \text {-groups participating in } \\
\text { intermolecular and intramolecular H-bonds }\end{array}$ \\
\hline 2920 & 0.12 & Stretching vibrations of bonds in $-\mathrm{CH}_{2}$ - groups \\
\hline 1633 & 0.23 & $\begin{array}{l}\text { Deformation vibrations of bonds in } \mathrm{H}-\mathrm{O}-\mathrm{H} \text { molecules due to } \\
\text { the presence of strongly bound water }\end{array}$ \\
\hline 1435 & 0.185 & Deformation vibrations of $-\mathrm{CH}_{2}-$ groups \\
\hline 1055 & 0.34 & Stretching vibrations of C-O bonds \\
\hline 610 & 0.22 & Deformation vibrations of C-H bonds \\
\hline
\end{tabular}




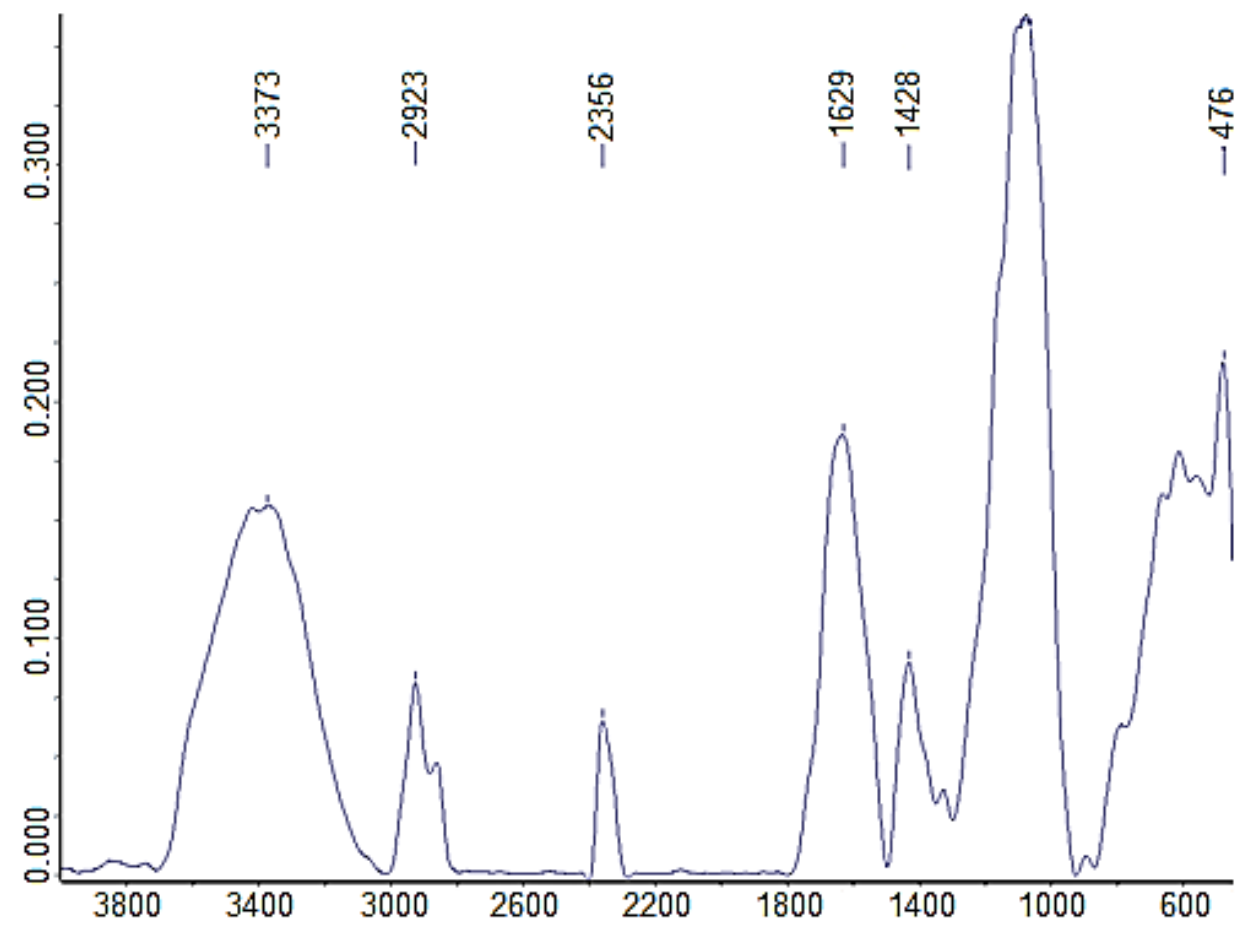

Fig. 2. IR spectrum of a composite from waste cotton on liquid glass.

\begin{tabular}{|c|c|c|}
\hline \multicolumn{3}{|c|}{ Table 4. Absorption bands of a composite of waste cotton on liquid glass } \\
\hline $\begin{array}{c}\text { Band position, } \\
\text { cm }^{-1}\end{array}$ & $\begin{array}{c}\text { Absorption } \\
\text { intensity, } \%\end{array}$ & Assignment of absorption bands \\
\hline $\mathbf{3 3 7 3}$ & 0.160 & $\begin{array}{c}\text { Stretching vibrations of OH-groups participating in } \\
\text { intermolecular and intramolecular } \mathrm{H} \text {-bonds }\end{array}$ \\
\hline $\mathbf{2 9 2 3}$ & 0.081 & Stretching vibrations of bonds in $-\mathrm{CH}_{2}$ - groups \\
\hline $\mathbf{2 3 5 6}$ & 0.062 & Stretching vibrations of bonds in $-\mathrm{CH}_{2}$ - groups \\
\hline $\mathbf{1 6 2 9}$ & 0.183 & $\begin{array}{r}\text { Deformation vibrations of bonds in } \mathrm{H}-\mathrm{O}-\mathrm{H} \text { molecules due to } \\
\text { the presence of strongly bound water }\end{array}$ \\
\hline $\mathbf{1 4 2 8}$ & 0.090 & Deformation vibrations of $-\mathrm{CH}_{2}$ - groups \\
\hline $\mathbf{1 0 7 2}$ & 0.360 & Stretching vibrations of Si-O-Si bonds \\
\hline $\mathbf{4 7 6}$ & 0.218 & Stretching vibrations of $\mathrm{Si}-\mathrm{O}$ bonds \\
\hline
\end{tabular}

Table 5. Absorption bands of a composite from cotton waste on aluminochromophosphate

\begin{tabular}{|c|c|c|}
\hline $\begin{array}{c}\text { Band position, } \\
\mathrm{cm}^{-1}\end{array}$ & $\begin{array}{c}\text { Absorption } \\
\text { intensity, } \%\end{array}$ & Assignment of absorption bands \\
\hline $\mathbf{3 4 0 2}$ & 0.155 & $\begin{array}{c}\text { Stretching vibrations of OH-groups participating in } \\
\text { intermolecular and intramolecular H-bonds }\end{array}$ \\
\hline $\mathbf{2 9 1 9}$ & 0.057 & Stretching vibrations of bonds in $-\mathrm{CH}_{2}$ - groups \\
\hline $\mathbf{1 6 5 2}$ & 0.150 & $\begin{array}{c}\text { Deformation vibrations of bonds in } \mathrm{H}-\mathrm{O}-\mathrm{H} \text { molecules due to } \\
\text { the presence of strongly bound water }\end{array}$ \\
\hline $\mathbf{1 4 4 3}$ & 0.070 & Deformation vibrations of $-\mathrm{CH}_{2}$ - groups \\
\hline $\mathbf{1 0 6 4}$ & 0.210 & Stretching vibrations of $\mathrm{P}-\mathrm{O}$ bonds \\
\hline $\mathbf{5 6 7}$ & 0.178 & Stretching vibrations of $\mathrm{Al}-\mathrm{O}$ bonds \\
\hline
\end{tabular}


Table 6. Absorption bands of a composite from cotton waste on a phenol-formaldehyde binder

\begin{tabular}{|c|c|c|}
\hline $\begin{array}{c}\text { Band position, } \\
\mathrm{cm}^{-1}\end{array}$ & $\begin{array}{c}\text { Absorption } \\
\text { intensity, } \%\end{array}$ & Assignment of absorption bands \\
\hline $\mathbf{3 3 6 6}$ & 0.208 & $\begin{array}{r}\text { Stretching vibrations of OH-groups participating in } \\
\text { intermolecular and intramolecular H-bonds }\end{array}$ \\
\hline $\mathbf{2 9 2 4}$ & 0.092 & Stretching vibrations of bonds in $-\mathrm{CH}_{2}$ - groups \\
\hline $\mathbf{1 6 4 1}$ & 0.235 & $\begin{array}{r}\text { Deformation vibrations of bonds in } \mathrm{H}-\mathrm{O}-\mathrm{H} \text { molecules due to } \\
\text { the presence of strongly bound water }\end{array}$ \\
\hline $\mathbf{1 4 3 7}$ & 0.138 & Deformation vibrations of $-\mathrm{CH}_{2}$ - groups \\
\hline $\mathbf{1 0 5 5}$ & 0.283 & Stretching vibrations of $\mathrm{C}-\mathrm{O}$ bonds \\
\hline $\mathbf{6 0 7}$ & 0.080 & Deformation vibrations of $\mathrm{C}-\mathrm{H}$ bonds \\
\hline
\end{tabular}

\begin{tabular}{|c|c|c|}
\hline \begin{tabular}{|c|}
$\begin{array}{c}\text { Band position, } \\
\mathrm{cm}^{-1}\end{array}$ \\
\end{tabular} & $\begin{array}{l}\text { Absorption } \\
\text { intensity, } \%\end{array}$ & Assignment of absorption bands \\
\hline 3350 & 0.270 & $\begin{array}{l}\text { Stretching vibrations of OH-groups participating in } \\
\text { intermolecular and intramolecular H-bonds }\end{array}$ \\
\hline 2923 & 0.083 & Stretching vibrations of bonds in $-\mathrm{CH}_{2}$ - groups \\
\hline 1655 & 0.360 & $\begin{array}{l}\text { Deformation vibrations of bonds in } \mathrm{H}-\mathrm{O}-\mathrm{H} \text { molecules due to } \\
\text { the presence of strongly bound water }\end{array}$ \\
\hline 1439 & 0.100 & Deformation vibrations of $-\mathrm{CH}_{2}$ - groups \\
\hline 1255 & 0.089 & Deformation vibrations of $-\mathrm{CH}_{2}$ - groups \\
\hline 1051 & 0.310 & Stretching vibrations of C-O bonds \\
\hline 611 & 0.230 & Deformation vibrations of C-H bonds \\
\hline
\end{tabular}

\section{Conclusions}

The use of cellulose-containing industrial waste in the production of heat-insulating materials solves the problems of developing resource-saving technologies. To ensure effective and stable thermal insulation properties, it is proposed to solve the problem of increasing the water resistance of composites from cellulose-containing waste by using hydrolytically stable binders.

The study of the structure of the material showed that the hydrophilic properties of composites from cellulose-containing waste are due to the supramolecular structure of cellulose, the presence of regions in the microstructure that can absorb moisture. Monoadsorbed water is tightly bound to active hydroxyls in the amorphous region of the cellulose of the filler.

The coefficient of thermal conductivity of composites from cellulose-containing waste varies depending on the type of filler by $0.01 \ldots 0.016 \mathrm{~W} / \mathrm{m} \cdot \mathrm{K}$, which is comparable to random scattering in the experiment, caused, among other factors, by the influence of the device error.

Thus, the experimental data obtained make it possible to recommend composite board materials based on phenol-formaldehyde binder, liquid glass, alumochromophosphate, and cellulose-containing waste filler, including soft wood waste and irrecoverable waste from spinning of flax and cotton fiber, for use as a heat-insulating element of building structures. 


\section{References}

1. S. V. Fedosov, V. N. Fedoseev, A. B. Petrukhin, L. A. Oparina, Energy efficiency of buildings, structures and structures for industrial and agricultural purposes, in Collection of scientific papers of the Russian Academy of Architecture and Building Sciences, Moscow (2020)

2. M. Yu. Slesarev, MGSU Bulletin. 3, 7 (2007)

3. V. I. Telichenko, A. L. Bolsherotov, Housing construction. 12, 2 (2010)

4. Yu. M. Bazhenov, A. M. Danilov, E. V. Korolev, I. A. Garkina, Regional architecture and construction. 1, 45 (2006)

5. Yu. M. Bazhenov, I. A. Garkina, A. M. Danilov, E. V. Korolev, Systems analysis in building materials science, Moscow (2012)

6. B. M. Rumyantsev, A. D. Zhukov, T. V. Smirnova, Internet Bulletin VolgGASU. 4(35), $3(2014)$

7. S. V. Fedosov, V. G. Kotlov, M. A. Ivanova, Housing construction. 12, 20 (2017)

8. S. V. Fedosov, N. R. Poroshin, N. N. Elin, V. E. Mizonov, Civil Engineers Bulletin. 3(28), 37 (2011)

9. I. V. Susoeva, T. N. Vakhnina, A. A. Titunin, J. A. Asatkina, Magazine of Civil Engineering. 3(71), 39 (2017)

10. S. V. Fedosov, A. A. Sakharov, N. N. Elin, V. E. Mizonov, Civil Engineers Bulletin. 1(36), 32 (2013)

11. Yu. B. Grunin, L. Yu. Grunin, V. I. Talantsev, E. A. Nikolskaya, D. S. Masas Biophysics. 1(60), 53 (2015)

12. Yu. B. Grunin, T. Yu. Grunina, M. S. Ivanova, S. V. Fedosov, V. G. Kotlov, Proceedings of higher educational institutions. Textile technology. 5(383), 124 (2019)

13. Yu. B. Grunin, M. S. Ivanova, D. S. Masas, L. Yu.Grunin, Biophysics. 6(64), 1066 (2019)

14. Yu. B. Grunin, M. S. Ivanova, D. S. Masas, L. Yu. Grunin, Physical Chemistry Journal. 4(94), 528 (2020)

15. V. I. Azarov, A. B. Burov, A. B. Obolenskaya, Chemistry of wood and synthetic polymers, Saint Petersburg (1999)

16. Yu. B. Grunin, L. Yu. Grunin, N. N. Sheveleva, D. S. Masas, S. V. Fedosov, V. G. Kotlov, Proceedings of higher educational institutions. Textile technology. 2(368), 233 (2017)

17. S. V. Fedosov, V. G. Kotlov, R. M. Aloyan, M. V. Bochkov, M. A. Ivanova, Proceedings of higher educational institutions. Textile technology. 5(365), 90 (2016)

18. Jinchun Zhu, Materials. 6, 5171 (2013)

19. Vistasp M. Karbhari, Durability of composites for civil structural applications, Elsevier Science. (2007)

20. B. S. Batalin, M. P. Krasnovskikh, Construction Materials. 8, 64 (2014)

21. T. N. Vakhnina, I. V. Susoeva, A. A. Titunin, IOP Conference Series: Materials Science and Engineering. 022005 (2019)

22. V. P. Yartsev, A. M. Dorofeev, ACADEMIA. Architecture and construction. 3, 604 (2010) 